\title{
Investment performance measurement of new generation mobile communication networks based on dynamic DEA model
}

\author{
Yu Du*, Xiaohang Zhang, Zhengren Li and Ling Wu
}

\begin{abstract}
With the fast development of the mobile internet in recent years, the new generation mobile communication networks as the basic supporting have received widespread attentions. During the upgrading period of new generation networks, the telecom operators need to grasp the network investment performance, which is one of the key factors for deploying the new generation networks and arranging new services effectively. In this paper, first, we propose a method based on the dynamic DEA model and the sensitivity analysis to measure the network investment performance of telecom operators, which gives the managers and researchers insight into the changing process of the key influence factors on the investment performance. Then, we build the input-output indicators system of the DEA model from five dimensions, such as INVESTMENT, SUPPLY, ADOPTION, USAGE, and REVENUE, for a more complete and valid characterization to the network investment performance. At last, we apply the proposed method to conduct an empirical research on the operational data of one Chinese telecom operator from 2013 to 2015, which has been the initial launch phase of 4G network. Based on the result, we develop effective investment strategies for the upgrading period of networks, which also gives guidelines for the investment of $5 \mathrm{G}$ and other new generation networks in the future.
\end{abstract}

Keywords: Performance measurement, New generation networks, Telecom investment, DEA model, Sensitivity analysis

\section{Introduction}

Recently, the new generation mobile communication networks (hereinafter referred to as "new generation networks"), such as 3G, 4G, and 5G, play an important role in the advancement of mobile internet and have received a vital concern [1-3]. During the upgrading period of new generation networks, telecom operators tend to keep an eye on the network investment performance, which is one of the key factors for deploying the new generation networks and arranging new mobile data services (hereinafter referred to as "new service") effectively $[4,5]$. Network investment performance is an important component of performance measurement for telecom operators, which means degree of the force that investment portfolios of different network facilities driving the operational performance improvement $[4,6,7]$.

\footnotetext{
* Correspondence: dy@bupt.edu.cn

School of Economics and Management, Beijing University of Posts and Telecommunications, 10 Xi Tu Cheng Road, Beijing 100876, China
}

The methods for telecom performance measurement have been relatively mature in the recent years. Exploratory factor analysis and principal components analysis have been used widely in the performance measurement when the number of sub-indices and the relationships among them cannot be obtained through management experience and theory analysis. Structural equation modeling (SEM) is also a commonly used performance measurement method in telecommunication [8, 9]. Unfortunately, this method has been used only for analyzing the static data in previous studies. In this case, data envelopment analysis (DEA) model appears to have a significantly advantage over the other performance measurement methods from the point of efficiency [1012].

In this paper, we propose a method based on the dynamic DEA model and the sensitivity analysis to measure the network investment performance of telecom operators. Then, we build the input-output indicators 
system of the DEA model from five dimensions to measure the network investment performance more effectively. Finally, we make an empirical research to dynamically analyze $4 \mathrm{G}$ investment of one Chinese telecom operator, and the practical investment strategies during the upgrading period of the networks can be summarized, which can also give investment guidelines for $5 \mathrm{G}$ and other new generation networks in the future.

\section{Related work}

\subsection{Insight into telecom investment}

The investment in telecommunications infrastructure and network facilities is both an important handgrip to improve the services of telecom operators and the important foundation of local economic development [4, 5]. While more studies are aiming at telecom investment in the recent years, Aude et al. [13] analyzed a large number of investment cases of Telecom Multinational Enterprises in Africa from 2000 to 2015, found there had been existed a big gap between the final deal prices and local market contexts, and then analyzed the key factors that influencing deal prices. With mobile telecommunication investment cases in Africa from 2001 to 2011, Goodiel et al. [14] tried to provide a framework to analyze the influence factors of telecom investment. Based on the operational data of 23 European operators from 2003 to 2012, Wolfgang et al. [7] proposed a flexible accelerator model to analyze the investment of broadband service and investigated the effects of market competition and strategies on telecom investment. During the upgrading period of new generation networks, network investment performance is the key factor for the deployment of the new generation networks and also the important power to drive the new services. Unfortunately, there are few researches focused on this point.

\subsection{Performance measurement of telecom services}

The methods to measure the operational performance of telecom services have been developed very well in the recent years. Exploratory factor analysis and principal components analysis have been used commonly in the specific situation of performance measurement. Based on product market regulations and employment protection legislation, Nicoletti et al. [15] established an indicators system where factor analysis had been used to aggregate detailed indicators into a summary indicator, and components were weighted according to its contribution to the overall variance in the data. To measure the performance of telecom infrastructure, Adnan et al. [16] proposed providing a composite Telecommunication Index (TI) based on principal component analysis including a number of telecommunication sub-indices, such as fixed telephone networks, the Internet, and mobile networks. As the two methods are data-driven, management experience is hard to be considered in the modeling. Hence, they can only be deployed in the situation where the number of sub-indices and the relations among them cannot be obtained by management experience and theory analysis.

Another method that is been commonly used in performance measurement is structural equation modeling (SEM). To assess the availability, adoption, and use of telecommunication networks and services at the country level, Gerpott and Ahmadi [8] provided a second-order composite index (TDI). This indicator and sub-indices weights are calculated by the SEM method. And the weights of indicators or sub-indices entering into an overall TDI are varying with the socio-economic target criterion. To measure broadband development in the EU, Lemstra and Voogt [17] developed a performance index and a market model where the statistically significant factors and components in the path model were determined by SEM method. SEM can be also deployed in calculating the weight of indicators and sub-indices, and one or several overall indices measuring the performance of telecom operators. Unfortunately, SEM method is used more often to analyze static data in previous literature.

Recently, DEA model is used by many researchers to study the relative efficiency of telecom services. To obtain the efficiency rankings of operators, Debnath and Shankar [10] calculated the relative efficiency of Indian telecom operators based on DEA. To measure the efficiency of Taiwan telecom operators from 2001 to 2005, Yang and Chang [11] used a constant and variable returns to scale-based method. In order to increase the number of decision-making units, DEA window analysis is introduced in this research. To study the key factors influencing Indian consumers' buying behavior of telecom services, Kumar and Shankar [12] developed a framework based on fuzzy AHP and DEA model. Compared with other methods of performance measurement, DEA model appears to have a significantly advantage over the other methods from the point of efficiency.

\section{Methodology}

Constant returns to scale model (CRS) and variable returns to scale model (VRS) are the basic model of DEA $[18,19]$. In CRS model, suppose the number of decision-making units (DMU) is $n$, the number of inputs and outputs is $m$ and $s$. Denote the inputs and outputs as $X_{j}=\left(x_{1 j}, \cdots, x_{i j}, \cdots, x_{m j}\right)^{T}$ and $Y_{j}=\left(y_{1 j}, \cdots, y_{r j}, \cdots, y_{m j}\right)^{T}$ respectively, with $i=1, \cdots, m, r=1, \cdots, s$ and $j=1, \cdots, n$.

We need to endow appropriate weight for every inputs and outputs, the weights of $X_{i}$ and $Y_{r}$ are recorded as $v_{i}$ and $u_{r}$. Define $V=\left(v_{1}, \cdots, v_{m}\right)^{T}$ and $U=\left(u_{1}, \cdots, u_{s}\right)^{T}$. Then, the efficiency evaluation index of $D M U_{j}$ can be defined as follows: 


$$
h_{j}=\frac{U^{T} Y_{j}}{V^{T} X_{j}}=\frac{\sum_{r=1}^{s} u_{r} y_{r j}}{\sum_{i=1}^{m} v_{i} x_{i j}}, j=1, \cdots, n,
$$

Next, we can evaluate the efficiency of $\operatorname{DMU}_{j_{0}}\left(1 \leq j_{0} \leq\right.$ $n$ ), and the CRS model as follows:

$$
\begin{aligned}
& \max \frac{\sum_{r=1}^{s} u_{r} y_{r j 0}}{\sum_{i=1}^{m} v_{i} x_{i j 0}}=V_{\bar{P}} \\
& (\bar{P})\left\{\quad \frac{\sum_{r=1}^{s} u_{r} y_{r j}}{\sum_{i=1}^{m} v_{i} x_{i j}} \leq 1, \quad j=1, \cdots, n\right. \\
& u_{r} \geq 0, \quad r=1, \cdots, s \\
& v_{i} \geq 0, \quad i=1, \cdots, m
\end{aligned}
$$

By Charnes-Cooper transform [18, 20, 21], we can set the following variables:

$$
\left\{\begin{array}{c}
t=\frac{1}{V^{T} X_{0}} \\
\omega=T V \\
\mu=T U
\end{array}\right.
$$

Equation (2) can be transformed to an equivalent linear programming problem, as follows:

$$
\begin{gathered}
\max \mu^{T} Y_{0}=V_{P} \\
(P)\left\{\begin{array}{c}
\text { s.t. } \bar{\omega}^{T} X_{j}-\mu^{T} Y_{j} \geq 0, \quad j=1,2, \cdots, n \\
\bar{\omega}^{T} X_{0}=1 \\
\omega \geq 0, \mu \geq 0
\end{array}\right.
\end{gathered}
$$

On the basis of the dual algorithm for general linear programming, the dual programming of the model $(P)$ can be transformed as follows:

$$
\begin{gathered}
\min \theta=V_{D^{0}} \\
\text { s.t. } \sum_{j=1}^{n} \lambda_{j} X_{j}+\theta X_{0} \leq 0 \\
\left(D^{0}\right)\left\{\quad \sum_{j=1}^{n} \lambda_{j} Y_{j} \geq Y_{0}\right. \\
\lambda_{j} \geq 0, \quad j=1, \cdots, n
\end{gathered}
$$

Then, the slack variables should been introduced into the model above, such as $s^{+} \geq 0, s^{-} \geq 0, s^{+}\left(s_{1}^{+}, s_{2}^{+}, \ldots, s_{s}^{+}\right)$, $s^{-}\left(s_{1}^{-}, s_{2}^{-}, \ldots, s_{m}^{-}\right)$, and the input -DEA model as follows:

$$
\begin{gathered}
\min \theta=V_{D^{1}} \\
\text { s.t. } \sum_{j=1}^{n} \lambda_{j} X_{j}+s^{-}=\theta X_{0} \\
\left(D^{1}\right)\left\{\quad \sum_{j=1}^{n} \lambda_{j} Y_{j}-s^{+}=Y_{0}\right. \\
\lambda_{j} \geq 0, \quad j=1, \cdots, n \\
s^{+} \geq 0, s^{-} \geq 0
\end{gathered}
$$

The CRS model can be revised to VRS model by adding an assumption of convexity [19], i.e., $\sum_{i=1}^{n} \lambda_{i}=1$, as shown in the following:

$$
\begin{gathered}
\min \theta=V_{G^{1}} \\
\text { s.t. } \sum_{j=1}^{n} \lambda_{j} X_{j}+s^{-}=\theta X_{0} \\
\left(G^{1}\right)\left\{\quad \sum_{j=1}^{n} \lambda_{j} Y_{j}-s^{+}=Y_{0}\right. \\
\sum_{j=1}^{n} \lambda_{j}=1 \\
\lambda_{j} \geq 0, \quad j=1, \cdots, n \\
s^{+} \geq 0, \quad s^{-} \geq 0
\end{gathered}
$$

The CRS model and VRS model can be used to calculate the technical efficiency (TE) and pure technical efficiency (PTE) of each DMU, and scale efficiency (SE) can be calculated as follows:

$$
\text { scale efficiency }(\mathrm{SE})=\frac{\text { technical efficiency }(\mathrm{TE})}{\text { pure technical efficiency }(\mathrm{PTE})}
$$

\section{Experiments}

\subsection{Data description and preparation}

The original dataset used in this study contains monthly operating data from 31 provincial companies of one Chinese telecom operator during the years 2013-2015. The preprocessing of time series data commonly involves two steps: handling missing values and eliminating seasonal effects. Firstly, linear interpolation method has been used to replace few missing values in the dataset [22]. Then we use Classical Seasonal Decomposition by Moving Averages method to eliminate seasonal effects in the dataset, which decomposes a time series data into seasonal, trend, and irregular components [23].

\subsection{Experimental design}

In order to measure the network investment performance more effectively, the input indicators of the DEA model should be cover variety of telecom investments in network facilities, and the output indicators should be set to describe the operational performance of telecom services completely and validly $[8,24]$. Therefore, we build the input-output indicators system of the DEA 
model (shown in Table 1) from five dimensions, such as INVESTMENT, SUPPLY, ADOPTION, USAGE, and REVENUE. The investment indicators (such as "I1 investment in wireless access network," "I2 investment in transmission network," "I3 investment in service network," "I4 investment in supporting network," and "I5 investment in construction") have been used as the inputs, which could cover variety of telecom investments in network facilities. To fully describe the operational performance of provincial companies, we grouped the outputs into four sub-indices labeled SUPPLY, ADOPTION, USAGE, and REVENUE $[4,8,25]$. SUPPLY measures the quality of networks to support telecom services, which includes two indicators: "S1 mobile phone exchange capacity" and "S2 size of carriers." ADOPTION is about the user size of telecom service and has been occurred frequently in the previous studies [8, 26-28]. In this study, ADOPTION sub-area includes two indicators: "A1 customer size" and "A2 customer size of cellular data service." USAGE measures the usage size of telecom services. Many researchers use the indicators of market penetration in this sub-area, such as the number of Internet users per 100 inhabitants [26, 29, 30]. However, it is inappropriate because there are wide differences among the consumer behaviors of telecom services [31]. In this sub-area, "U1 calls duration per month" and "U2 cellular data traffic per month" have been used. REVENUE sub-area includes the "R1 revenue per month" and " $R 2$ revenue of cellular data service per month," which are the oriented indicators of telecom services development.

Table 1 The inputs and outputs of the DEA model

\begin{tabular}{lc}
\hline Inputs & Outputs \\
\hline INVESTMENT & SUPPLY \\
I1 investment in wireless & S1 mobile phone exchange \\
access network & capacity \\
I2 investment in transmission & S2 size of carriers \\
network & \\
$\begin{array}{l}\text { I3 investment in service } \\
\text { network } \\
14 \text { investment in supporting } \\
\text { network } \\
\text { I5 investment in construction }\end{array}$ & ADOPTION \\
& A2 customer size \\
& Service \\
USAGE \\
U1 calls duration per month \\
U2 cellular data traffic per month \\
REVENUE \\
R1 revenue per month \\
R2 revenue of cellular data service \\
per month
\end{tabular}

The correlation test has been validated between inputs and outputs above, and the results are shown in Table 2. All of the correlation coefficients reject the null hypothesis on the 0.01 significance level, and it means that the inputs and outputs of the model are reasonable.

For this Chinese telecom operator, years 2013-2015 were the upgrading period of $4 \mathrm{G}$ network, and the period of most telecom projects was 1 year, such as base station construction and assessment. Therefore, this period could be divided into three annual stages: (1) This Chinese telecom operator begun building largescale trial 4G networks and launching pre-commercial service in 2013, so we named year 2013 as "preparation stage." (2) In 2014, 4G networks have been officially on use, and the operator obtained 1-year window to develop 4G without competition. Thus, year 2014 was named "the first year and the window stage." (3) This Chinese telecom operator entered into "competition stage," when the competitors launched their $4 \mathrm{G}$ service in 2015. The following parts would focus on the network investment performance of these three stages and summarize the investment strategies during the inception phase of the new services, which can give investment guidelines for $5 \mathrm{G}$ and other new generation networks.

\subsection{Empirical results and discussion}

\subsubsection{Network investment performance analysis}

As explained in Section 3, network investment performance contains three aspects: technical efficiency (TE), pure technical efficiency (PTE), and scale efficiency (SE). The annual average TE, PTE, and SE of 31 provincial

Table 2 The correlation test between inputs and outputs of the model

\begin{tabular}{lllllll}
\hline & & 11 & 12 & 13 & 14 & 15 \\
\hline S1 & Pearson correlation & 0.535 & 0.666 & 0.388 & 0.392 & 0.392 \\
& Sig. (two-tailed) & 0.000 & 0.000 & 0.000 & 0.000 & 0.000 \\
S2 & Pearson correlation & 0.600 & 0.705 & 0.390 & 0.354 & 0.412 \\
& Sig. (two-tailed) & 0.000 & 0.000 & 0.000 & 0.000 & 0.000 \\
A1 & Pearson correlation & 0.586 & 0.723 & 0.418 & 0.400 & 0.424 \\
& Sig. (two-tailed) & 0.000 & 0.000 & 0.000 & 0.000 & 0.000 \\
A2 & Pearson correlation & 0.584 & 0.725 & 0.422 & 0.399 & 0.418 \\
& Sig. (two-tailed) & 0.000 & 0.000 & 0.000 & 0.000 & 0.000 \\
U1 & Pearson correlation & 0.569 & 0.716 & 0.425 & 0.411 & 0.423 \\
& Sig. (two-tailed) & 0.000 & 0.000 & 0.000 & 0.000 & 0.000 \\
\multirow{2}{*}{ U2 } & Pearson correlation & 0.470 & 0.542 & 0.232 & 0.241 & 0.303 \\
& Sig. (two-tailed) & 0.000 & 0.000 & 0.000 & 0.000 & 0.000 \\
\multirow{2}{*}{ R1 } & Pearson correlation & 0.579 & 0.708 & 0.446 & 0.393 & 0.434 \\
& Sig. (two-tailed) & 0.000 & 0.000 & 0.000 & 0.000 & 0.000 \\
\multirow{2}{*}{ R2 } & Pearson correlation & 0.628 & 0.671 & 0.377 & 0.300 & 0.377 \\
& Sig. (two-tailed) & 0.000 & 0.000 & 0.000 & 0.000 & 0.000 \\
\hline
\end{tabular}


companies from 2013 to 2015 are shown in Table 3. Provincial company of Guangdong has consistently held the top spot for the 3 years, and the TE of Zhejiang, Jiangsu, Shandong, Sichuan, Henan, and Hebei has also been significantly higher than the other provincial companies. For simply research, we divide the all provincial companies into two groups depending on their TE, the above 7 companies are named group $\mathrm{A}$, and the others are group B.

The annual average TE, PTE, and SE of two groups from 2013 to 2015 are shown in Fig. 1. Group A is better overall than group $B$ in investment performance during the upgrading period of new generation networks. The result shows that the two groups do not have great difference in PTE, but have great difference in SE. This illustrates that group B should increase the investment during the upgrading period, and then the investment performance could be improved.

The TE of group A experienced the development process from slow decline to rapid growth, which presents V-shape tendency: The TE achieved 0.670 by 2014 and rose substantially in 2015, climbing to 0.777 . The TE of group B experienced from stability to rapid growth, the lowest point was 0.276 in 2013, and peaked at 0.356 in 2015.

In respect of PTE, both group A and B present Vshape tendency: The PTE of group A reached its lowest point in 2014, and the next year increased to 0.857 , which beyond the 2013 level. Group B also reached its nadir in 2014, and the next year went back to the level

Table 3 The annual average technical efficiency (TE), pure technical efficiency (PTE), and scale efficiency (SE) of 31 provincial companies from 2013 to 2015

\begin{tabular}{|c|c|c|c|c|c|c|c|c|c|}
\hline & \multicolumn{3}{|c|}{ Year 2013} & \multicolumn{3}{|c|}{ Year 2014} & \multicolumn{3}{|c|}{ Year 2015} \\
\hline & $\overline{\mathrm{TE}}$ & PTE & SE & $\mathrm{TE}$ & PTE & SE & $\overline{\mathrm{TE}}$ & PTE & SE \\
\hline Guangdong & 0.931 & 0.986 & 0.945 & 0.882 & 0.975 & 0.905 & 0.954 & 1.000 & 0.954 \\
\hline Sichuan & 0.853 & 0.897 & 0.950 & 0.797 & 0.846 & 0.941 & 0.821 & 0.847 & 0.966 \\
\hline Jiangsu & 0.653 & 0.736 & 0.882 & 0.642 & 0.716 & 0.892 & 0.809 & 0.817 & 0.990 \\
\hline Hebei & 0.642 & 0.812 & 0.786 & 0.600 & 0.788 & 0.759 & 0.661 & 0.861 & 0.767 \\
\hline Zhejiang & 0.628 & 0.785 & 0.794 & 0.636 & 0.743 & 0.854 & 0.844 & 0.866 & 0.973 \\
\hline Shandong & 0.601 & 0.764 & 0.786 & 0.618 & 0.783 & 0.786 & 0.693 & 0.784 & 0.884 \\
\hline Henan & 0.558 & 0.772 & 0.714 & 0.517 & 0.731 & 0.707 & 0.655 & 0.827 & 0.789 \\
\hline Fujian & 0.416 & 0.742 & 0.557 & 0.429 & 0.750 & 0.570 & 0.514 & 0.757 & 0.673 \\
\hline Liaoning & 0.405 & 0.776 & 0.518 & 0.366 & 0.757 & 0.483 & 0.506 & 0.762 & 0.655 \\
\hline Anhui & 0.403 & 0.768 & 0.524 & 0.364 & 0.738 & 0.493 & 0.460 & 0.771 & 0.596 \\
\hline Hunan & 0.393 & 0.765 & 0.511 & 0.372 & 0.732 & 0.505 & 0.457 & 0.775 & 0.589 \\
\hline Hubei & 0.385 & 0.753 & 0.512 & 0.383 & 0.723 & 0.529 & 0.497 & 0.776 & 0.639 \\
\hline Yunnan & 0.381 & 0.765 & 0.497 & 0.372 & 0.729 & 0.509 & 0.556 & 0.837 & 0.661 \\
\hline Neimenggu & 0.375 & 0.770 & 0.486 & 0.384 & 0.762 & 0.503 & 0.376 & 0.745 & 0.504 \\
\hline Shanghai & 0.370 & 0.743 & 0.496 & 0.361 & 0.752 & 0.480 & 0.409 & 0.752 & 0.545 \\
\hline Beijing & 0.351 & 0.745 & 0.470 & 0.401 & 0.769 & 0.514 & 0.506 & 0.790 & 0.635 \\
\hline Guizhou & 0.337 & 0.773 & 0.421 & 0.290 & 0.764 & 0.379 & 0.364 & 0.766 & 0.472 \\
\hline Xinjiang & 0.308 & 0.810 & 0.378 & 0.348 & 0.770 & 0.452 & 0.491 & 0.803 & 0.592 \\
\hline Guangxi & 0.307 & 0.796 & 0.386 & 0.310 & 0.741 & 0.418 & 0.374 & 0.752 & 0.496 \\
\hline Heilongjiang & 0.298 & 0.739 & 0.404 & 0.444 & 0.782 & 0.567 & 0.470 & 0.766 & 0.614 \\
\hline Shanxi & 0.295 & 0.770 & 0.383 & 0.302 & 0.731 & 0.412 & 0.430 & 0.756 & 0.548 \\
\hline Shaanxi & 0.294 & 0.767 & 0.382 & 0.307 & 0.736 & 0.417 & 0.382 & 0.756 & 0.506 \\
\hline Jiangxi & 0.283 & 0.757 & 0.374 & 0.326 & 0.720 & 0.452 & 0.393 & 0.716 & 0.549 \\
\hline Chongqing & 0.241 & 0.780 & 0.309 & 0.234 & 0.761 & 0.307 & 0.289 & 0.754 & 0.383 \\
\hline Jilin & 0.231 & 0.793 & 0.290 & 0.209 & 0.775 & 0.269 & 0.406 & 0.796 & 0.489 \\
\hline Gansu & 0.177 & 0.773 & 0.228 & 0.185 & 0.774 & 0.239 & 0.237 & 0.800 & 0.296 \\
\hline Tianjin & 0.143 & 0.815 & 0.176 & 0.131 & 0.807 & 0.163 & 0.146 & 0.816 & 0.178 \\
\hline Hainan & 0.100 & 0.829 & 0.121 & 0.096 & 0.826 & 0.116 & 0.112 & 0.832 & 0.134 \\
\hline Ningxia & 0.059 & 0.831 & 0.070 & 0.056 & 0.834 & 0.066 & 0.063 & 0.819 & 0.077 \\
\hline Qinghai & 0.047 & 0.831 & 0.056 & 0.058 & 0.799 & 0.073 & 0.073 & 0.806 & 0.091 \\
\hline Xizang & 0.035 & 0.856 & 0.040 & 0.033 & 0.856 & 0.038 & 0.043 & 0.856 & 0.050 \\
\hline
\end{tabular}



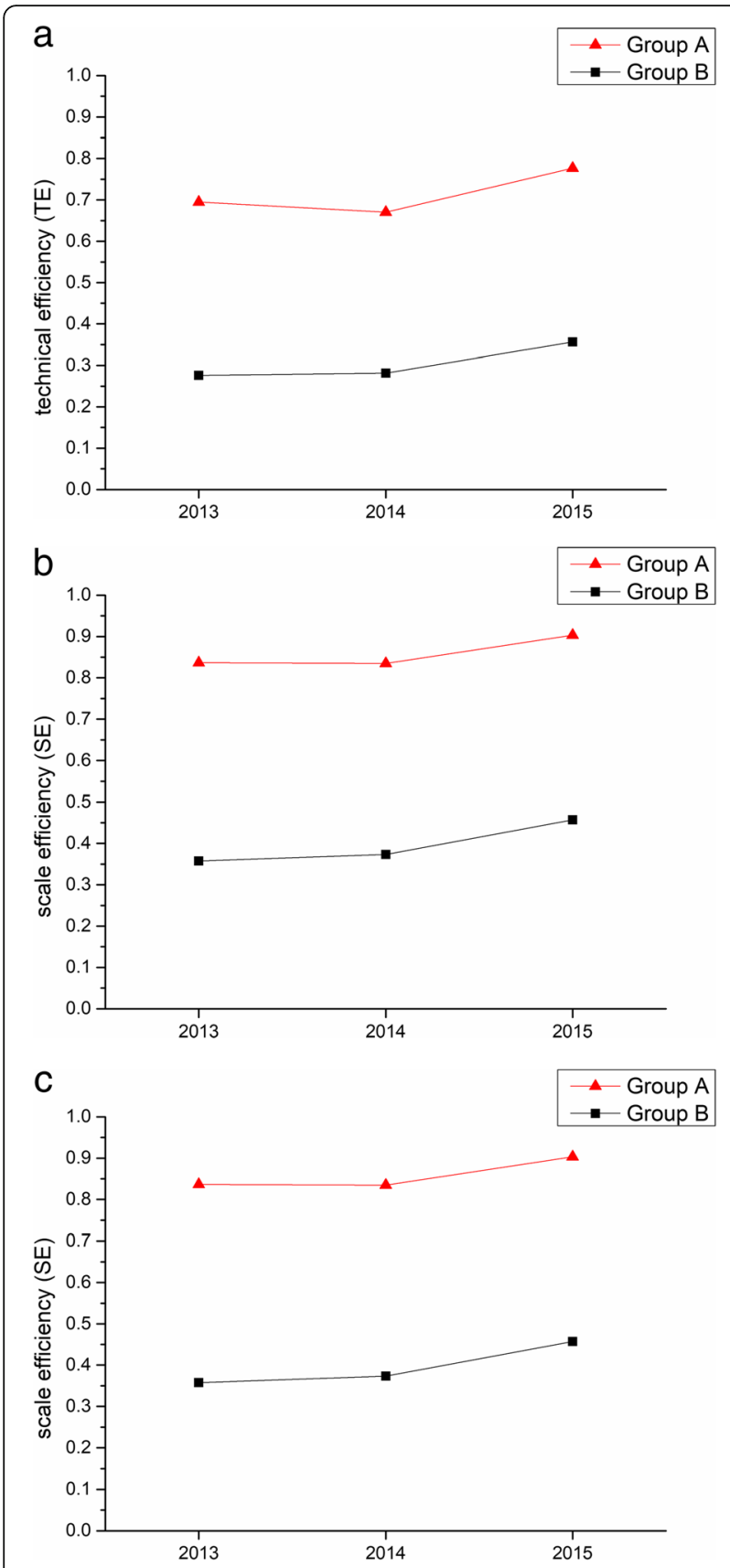

Fig. 1 The annual average TE, PTE, and SE of two groups from 2013 to 2015. a The annual average TE of the two groups from 2013 to 2015. Red line with up-triangle indicates the annual average TE of group A from 2013 to 2015. Black line with square indicates the annual average TE of group B from 2013 to 2015. b The annual average PTE of the two groups from 2013 to 2015. Red line with uptriangle indicates the annual average PTE of group A from 2013 to 2015. Black line with square indicates the annual average PTE of group B from 2013 to 2015. c The annual average SE of the two groups from 2013 to 2015. Red line with up-triangle indicates the annual average SE of group A from 2013 to 2015. Black line with square indicates the annual average SE of group B from 2013 to 2015 of 2013, reaching 0.782. It is shown that the technical ability of provincial companies falls slightly in the first year and window stage, subject to the influence of the networks update, and will be returned back in the competition stage. Group A is significantly more efficient than group B, and the PTE in the competition stage goes beyond the preparation stage. However, the PTE of group B in the competition stage has almost same number compared with the preparation stage.

In respect of $\mathrm{SE}$, both group $\mathrm{A}$ and $\mathrm{B}$ experienced from stability to rapid growth: The SE of group A achieved 0.835 by 2014 and rose substantially in 2015, climbing to 0.903 . The lowest point of group B was 0.358 in 2013 and peaked at 0.457 in 2015 . Besides, the proportions of diseconomies scale DMUs which due to increasing returns to scale (IRS) [18, 19] in group A from 2013 to 2015 were $79.76 \%, 84.52 \%$, and $73.80 \%$, on the other hand, the proportions of group B were $99.65 \%$, $100.00 \%$, and $99.31 \%$. This illustrates that lots of provincial companies in group A need properly raise the investment in the preparation and window stages. Most of provincial companies in group B should increase investment in all of three stages, so as to improve the network investment performance during the upgrading period of new generation networks.

\subsubsection{Influential factors analysis on network investment performance}

We deleted the inputs separately and put the other inputs into DEA model, and then calculated the percentage of difference between the new TE and the old one in order. These percentages represent the sensitivity of TE to the each input [32-34]. Generally speaking, the bigger the sensitivity coefficients, the more sensitive the investment performance is to the investment indicator, so that this indicator becomes more crucial to improve performance. The sensitivity of investment performance to each input investment indicator from 2013 to 2015 is shown in Fig. 2.

From 2013 to 2015, the investment performance of all provincial companies is most sensitive to the wireless access and transmission network investment. To guarantee the new services running smoothly, provincial companies should pay more attention to the wireless access and transmission network investment during the inception phase. The sensitivity of all provincial companies to the investment in wireless access network showed descend trend, and the sensitivity of group A is significantly higher than group B. It means that the wireless access network investment should be mainly focused on the prophase of the new services. Due to the larger number of users and better foundation of market, group A is more urgent for the new wireless access network. The sensitivity of all provincial companies to the investment 


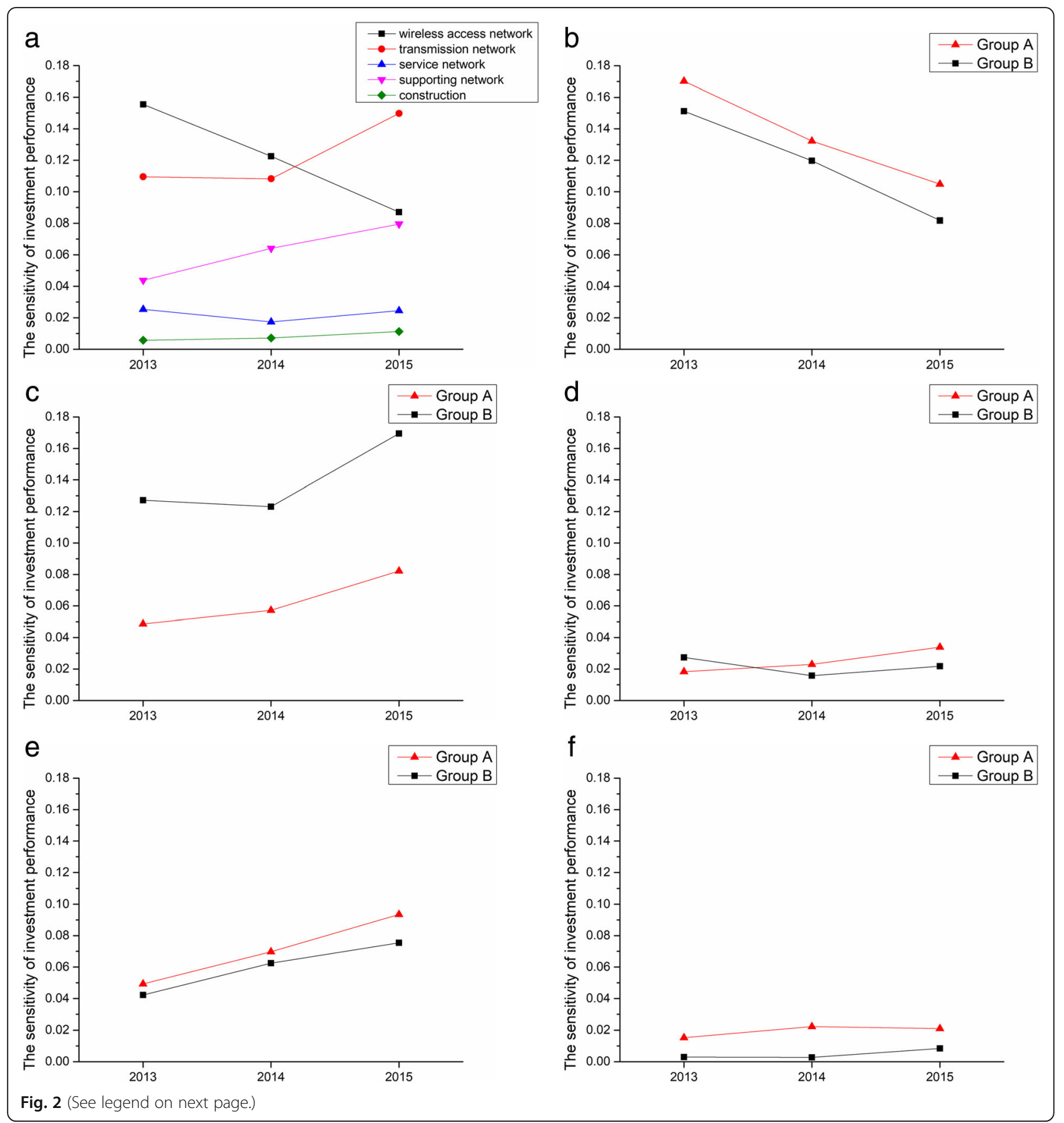




\section{(See figure on previous page.)}

Fig. 2 The sensitivity of investment performance to each input investment indicator from 2013 to 2015. a The sensitivity of investment performance of all provincial companies to each input investment indicator from 2013 to 2015. Black line with square indicates the sensitivity of investment performance to the investment in wireless access network. Red line with circle indicates the sensitivity of investment performance to the investment in transmission network. Blue line with up-triangle indicates the sensitivity of investment performance to the investment in service network. Purple line with down-triangle indicates the sensitivity of investment performance to the investment in supporting network. Green line with diamond indicates the sensitivity of investment performance to the investment in construction. $\mathbf{b}$ The sensitivity of investment performance of groups A and B to the investment in wireless access network from 2013 to 2015. Red line with up-triangle indicates the sensitivity of investment performance of group $A$ to the investment in wireless access network. Black line with square indicates the sensitivity of investment performance of group B to the investment in wireless access network. c The sensitivity of investment performance of groups A and B to the investment in transmission network from 2013 to 2015. Red line with up-triangle indicates the sensitivity of investment performance of group A to the investment in transmission network. Black line with square indicates the sensitivity of investment performance of group B to the investment in transmission network. $\mathbf{d}$ The sensitivity of investment performance of groups A and B to the investment in service network from 2013 to 2015. Red line with up-triangle indicates the sensitivity of investment performance of group A to the investment in service network. Black line with square indicates the sensitivity of investment performance of group B to the investment in service network. $\mathbf{e}$ The sensitivity of investment performance of groups A and B to the investment in supporting network from 2013 to 2015. Red line with up-triangle indicates the sensitivity of investment performance of group $A$ to the investment in supporting network. Black line with square indicates the sensitivity of investment performance of group B to the investment in supporting network. $\mathbf{f}$ The sensitivity of investment performance of groups A and B to the investment in construction from 2013 to 2015. Red line with up-triangle indicates the sensitivity of investment performance of group A to the investment in construction. Black line with square indicates the sensitivity of investment performance of group B to the investment

in construction

in transmission network increased appeared slowly first and fast afterwards, and the sensitivity of group B is significantly higher than group $\mathrm{A}$. It illustrates that the transmission network investment should be based on the development of the new services. The original transmission network only need modified slightly by the requirement of new services; thus, the transmission network investment of provincial companies should be based on the original network. By the weakness of original transmission network, the investment demand of group B is higher.

The underlying trend for the sensitivity of all provincial companies to the investment in supporting network rose steadily, and the sensitivity of group A is significantly higher than group $B$. There is a high correlation between the supporting network investment demand and the development of new services, so that the investment strength should be increased gradually with the new services promotion, avoiding with up-front investment lower investment performance. The sensitivity to the service network investment exists some difference in groups A and B: the sensitivity of group A showed rising trend; meanwhile, group B was more stable. With the better foundation of the market, group A innovates the product range and business model of the new services at first, and the demand of service network investment could be driven.

The sensitivity of all provincial companies to the construction was the lowest, and the sensitivity of group A is a little higher than group B. During the inception phase of the new services, the construction is the lowest priority investment compared with the basic network.

\section{Conclusions and future works}

In this paper, we propose a method based on the dynamic DEA model and the sensitivity analysis to measure the network investment performance of telecom operators, which can give the managers and researchers insight into the changing process of the key influence factors on the network investment performance. Then, we build the input-output indicators system of the DEA model from five dimensions, such as INVESTMENT, SUPPLY, ADOPTION, USAGE, and REVENUE, for a more complete and valid characterization to the network investment performance. At last, we apply the proposed method to conduct an empirical research on the operational data of one Chinese telecom operator from 2013 to 2015, which has been the initial launch phase of 4G network, and the practical investment strategies during the upgrading period of new generation networks can be summarized as follows: (1) Provincial companies of telecom operators should pay more attention to the wireless access and transmission network investment during the upgrading period. (2) The wireless access network investment should be mainly focused on the prophase of the new services. (3) In general, provincial companies fall into two groups according to their investment performance, leading group named group A, and the other named group B. Group A is more urgent for the new wireless access network. (4) The transmission network investment should be based on the development of the new services and original network. By the weakness of original transmission network, the investment demand of group B is higher. (5) Supporting network investment should be increased gradually with the new services promotion, avoiding with up-front investment lower investment performance. (6) Group A innovates the product range and business model of the new service at first, and the demand of service network investment could be driven. (7) The 
construction is the lowest priority investment compared with the basic networks.

In future work, more dimensions of outputs could be introduced into the model. Researchers can use this model to 5G investment empirical study, and some of the investment strategies would be improved.

\section{Abbreviations}

CRS: Constant returns to scale model; DEA: Data envelopment analysis; DMU: Decision-making units; IRS: Increasing returns to scale; PTE: Pure technical efficiency; SE: Scale efficiency; SEM: Structural equation modeling; TE: Technical efficiency; TI: Telecommunication Index; VRS: Variable returns to scale model

\section{Acknowledgements}

Not applicable

\section{Authors' contributions}

$Y D$ is the main writer of this paper. He proposed the main idea and analyzed the result. XZ gave good suggestions on the innovation of the paper. ZL and LW put forward some suggestions for the design of the experimental part. All authors read and approved the final manuscript.

\section{Availability of data and materials}

The datasets analyzed during the current study are not publicly available since involved a confidentiality agreement but are available from the corresponding author on reasonable request.

\section{Competing interests}

The authors declare that they have no competing interests.

Received: 3 July 2019 Accepted: 10 October 2019

Published online: 27 November 2019

\section{References}

1. M. Gramaglia, C.J. Bernardos, M. Calderon, Seamless internet 3 G and opportunistic WLAN vehicular connectivity. Eurasip Journal on Wireless Communications \& Networking 1(183) (2011). https://doi.org/10.1186/16871499-2011-183

2. S Z Yang, The marketing chain in the mobile Internet era. 2011 International Conference on Machine Learning and Cybernetics (2011). doi:https://doi. org/10.1109/ICMLC.2011.6016917.

3. W Jia, Enlightenment from the innovative application of $4 \mathrm{G}$ communication technology in the mobile library. 2016 International Conference on Smart City and Systems Engineering (2016). doi:https://doi.org/10.1109/ICSCSE. 2016.0050 .

4. Harb, Georges, The economic impact of the Internet penetration rate and telecom investments in Arab and Middle Eastern countries. Economic Analysis and Policy (2017). doi:https://doi.org/10.1016/ s0313592617300334.

5. A. Coban, F. Yigit, H. Kalkavan, et al., Macroeconomic facts for telecom industry in MINT countries. Procedia Economics \& Finance 39, 156-164 (2016)

6. J. Bruce, Feibel, Investment Performance Measurement (Wiley, New York, 2003)

7. W. Briglauera, A. Haxhimusa, K. Guglerb, Facility- and service-based competition and investment in fixed broadband networks: lessons from a decade of access regulations in the European Union member states. Telecommunications Policy 40(8), 729-742 (2016)

8. T.J. Gerpott, N. Ahmadi, Advancement of indices assessing a nation's telecommunications development status: a PLS structural equation analysis of over 100 countries. Telecommunications Policy 39(2), 93-111 (2015)

9. V. Kyriakidou, C. Michalakelis, T. Sphicopoulos, Assessment of information and communications technology maturity level. Telecommunications Policy 37(1), 48-62 (2013)

10. R.M. Debnath, R. Shankar, Benchmarking telecommunication service in India. Benchmarking: An International Journal 15(5), 584-598 (2008). https://doi. org/10.1108/14635770810903169

11. H.H. Yang, C.Y. Chang, Using DEA window analysis to measure efficiencies of Taiwan's integrated telecommunication firms. Telecommunications Policy 33(1), 98-108 (2009). https://doi.org/10.1016/j.telpol.2008.11.001
12. A. Kumar, R. Shankar, R.M. Debnath, Analyzing customer preference and measuring relative efficiency in telecom sector: a hybrid fuzzy AHP/DEA study. Telematics and Informatics 32(3), 447-462 (2015). https://doi.org/10. 1016/j.tele.2014.10.003

13. A. Schoentgen, L. Gille, Valuation of telecom investments in sub-Saharan Africa. Telecommunications Policy (2017). https://doi.org/10.1016/ s0308596117301994

14. G.C. Moshi, H.J. Mwakatumbula, Effects of political stability and sector regulations on investments in African mobile markets. Telecommunications Policy 41, 7-8 (2017)

15. G Nicoletti, S Scarpetta, O Boylaud, Summary indicators of product market regulation with an extension to employment protection legislation. OECD Economics Department Working Papers (2000). doi:https:/doi.org/10.2139/ ssin.201668

16. A. Al-Mutawkkil, A. Heshmati, J. Hwang, Development of telecommunication and broadcasting infrastructure indices at the global level. Telecommunications Policy 33(3-4), 176-199 (2009)

17. W. Lemstra, B. Voogt, N. Van Gorp, Measuring broadband in Europe: development of a market model and performance index using structural equations modelling. Telecommunications Policy 39(3-4), 253-268 (2015)

18. A. Charnes, W.W. Cooper, E. Rhodes, Measuring the efficiency of decision making units. European Journal of Operational Research 2(6), 429-444 (1978)

19. RD Banker, A. Charnes, W.W. Cooper, Some models for estimating technical and scale inefficiencies in data envelopment analysis. Management Science 30(9), 1078-1092 (1984)

20. A. Charnes, W.W. Cooper, An explicit general solution in linear fractional programming. Naval Research Logistics Quarterly 20(3), 449-467 (1973). https://doi.org/10.1002/nav.3800200308

21. A. Charnes, W.W. Cooper, Programming with linear fractional functionals. Naval Research Logistics 9(3-4), 181-186 (1962). https://doi.org/10.1002/nav. 3800090303

22. E. Meijering, A chronology of interpolation: from ancient astronomy to modern signal and image processing. Proceedings of the IEEE 90(3), 319342 (2002)

23. Kendall, G Maurice, The advanced theory of statistics (C. Griffin, 1979).

24. Z. Xiaohang, D. Yu, L. Zhengren, et al., Analyzing the operational performance migration of telecom operators. China Communications 15(6), 139-157 (2018). https://doi.org/10.1109/CC.2018.8398511

25. J. James, The ICT Development Index and the digital divide: how are they related? Technological Forecasting and Social Change 79(3), 587-594 (2012)

26. R.L. Katz, P. Koutroumpis, Measuring digitization: a growth and welfare multiplier. Technovation 33(10-11), 314-319 (2013)

27. P. Hanafizadeh, M.R. Hanafizadeh, M. Khodabakhshi, Extracting core ICT indicators using entropy method. The Information Society 25(4), 236-247 (2009)

28. L Waverman, K Dasgupta, J Rajala, Connectivity scorecard. (IOP Publishing Berkley, 2011) http://academy.tu.int/moodle/pluginfile.php/38538/mod_ resource/content/1/ConnectivityScorecard.pdf.

29. M. Billon, R. Marco, F. Lera-Lopez, Disparities in ICT adoption: a multidimensional approach to study the cross-country digital divide. Telecommunications Policy 33(10), 596-610 (2009)

30. G. Bruno, E. Esposito, A. Genovese, et al., A critical analysis of current indexes for digital divide measurement. The Information Society $27(1)$, 1628 (2011)

31. Orbicom, Monitoring the digital divide and beyond. (IOP Publishing Montreal Orbicom, 2003) http://orbicom.uqam.ca/upload/files/research_ projects/2003_dd_pdf_en.pdf.

32. A. Saltelli, Sensitivity analysis for importance assessment. Risk analysis: an official publication of the Society for Risk Analysis 22(3), 579-590 (2002). https://doi.org/10.1111/0272-4332.00040

33. A. Saltelli, M. Ratto, T. Andres, et al., Global Sensitivity Analysis: the Primer (Wiley, New York, 2008)

34. D.J. Pannell, Sensitivity analysis of normative economic models: theoretical framework and practical strategies. Agricultural Economics of Agricultural Economists 16(2), 139-152 (1996). https://doi.org/10.1016/501695150(96)01217-0

\section{Publisher's Note}

Springer Nature remains neutral with regard to jurisdictional claims in published maps and institutional affiliations. 